\title{
Investigation of Injuries Due to Different Types of Button Batteries Stuck in Ear Canals
}

\author{
Gökhan Akgül ${ }^{1}$ (D), Mustafa Bakırtaş² (D) \\ ${ }^{1}$ University of Health Sciences, Samsun Health Practices and Research Center, Department of Otorhinolaryngology, Samsun, Turkey \\ ${ }^{2}$ University of Health Sciences, Samsun Health Practices and Research Center, Department of Pathology, Samsun, Turkey
}

ORCID ID: G.A. 0000-0003-0699-6585; M.B. 0000-0003-3185-6947

Citation: Akgul G, Bakirtas M. Investigation of injuries due to different types of button batteries stuck in ear canals. Tr-ENT. Published online December 16, 2021. https://doi.org/10.26650/Tr-ENT.2021.1027401

\begin{abstract}
Objective: Button Batteries (BB) stuck in the Ear Canal (EC) have a special importance among foreign bodies in terms of causing complications depending on the length of time they remain in place, especially in children. In the present study, the purpose was to compare the damaging effects of frequently used BB chemicals on EC and the differences among them.

Material and Methods: After 4 EC models prepared from freshly frozen cadaveric bovine ears were thawed, Lithium, Alkaline, Silver-oxide, and Zinc-air BBs with similar size were placed respectively in the canals as the negative poles in contact with the skin. The voltage, tissue temperatures, and $\mathrm{pHs}$ of the BBs were measured and visual damage was photographed at the $3^{\text {rd }}, 6^{\text {th }}, 12^{\text {th }}$, and $24^{\text {th }}$ hours. The BBs were removed at the end of the $24^{\text {th }}$ hour, and EC models were examined histopathologically in a single-blind manner.

Results: Although the visual damage could be observed in the first 1.5 hours in ECs with Lithium, Alkaline, and Silver-oxide BBs, it was observed that this time extended to 2.5 hours in Zinc-air. The highest $\mathrm{pH}$ value was measured in lithium BB at the end of 24 hours, and the lowest pH value was measured in Zinc-air BB. The least voltage loss was measured in alkaline BB, and not all BB types caused significant changes in tissue temperatures for 24 hours. No significant tissue necrosis depth was detected in Zinc-air BB, but it was most common in Lithium, Silver-oxide, and Alkaline BBs, respectively.

Conclusion: All BB chemicals, especially Lithium BB, might cause alkaline necrosis at varying degrees by increasing the pH in EC models without any heat change. Zinc-air BBs, which are generally used in hearing aids, appear to have less damage potential compared to others.
\end{abstract}

Keywords: Button battery, foreign bodies, ear canal, alkaline necrosis

\section{INTRODUCTION}

The upper aerodigestive system and EC foreign bodies pose a common problem, especially in the patient group of pediatric age (1). Foreign bodies are detected in advanced age groups, especially in mental retardation and patients with Alzheimer's Disease. Unlike other foreign bodies, BBs can cause serious complications $(2,3)$.

The use of BBs in devices such as hearing aids, household appliances, electronic toys, watches, and digital gadgets has increased (4). The shape and bright form of BBs attract the attention, especially from children (5). BB foreign bodies can be asymptomatic or have dangerous effects, which can cause fatal outcomes $(4,6)$. The clinical course of BBs depends on many factors (5). These factors include time; localization; type, size, and voltage of the battery; humidity; and chemical contents $(5,7)$. Although BBs that are stuck in EC can often be detected and removed early, cases that are admitted with complications were also reported. In the ECs of young children, the mentally retarded, and elderly dementia patients, the diagnosis of BBs may be delayed if there is no eyewitness, and the risk of complications because of the long stay increases (8). Also, the bloody and moist environment created in ECs when non-specialists try to remove BBs may cause rapid discharge from the BBs and increase the damage. Potential complications caused by BBs trapped in the EC include stenosis of the canal, tympanic membrane perforation, hearing loss, and ossicular and vestibular damage (9).

Four different chemicals, lithium (CR), alkaline (LR), zincair (PR), and silver oxide (SR), are frequently used in the $B B$ 
industry. BBs might have similar sizes but different voltages and chemical contents. Although Lithium and Alkaline BBs are mostly used in small electronic devices (i.e. watches, toys, etc.), Zinc-air constitutes most of the chemicals often used in hearing aids (10).

The damage caused by BBs and other foreign bodies in EC was discussed in the literature with case reports (11). The damaging effects of commonly used BB chemicals and the differences between them were investigated in the present study with in vitro EC models.

\section{MATERIALS AND METHODS}

The ethical aspect of this study was approved by the Ondokuz Mayıs University (OMU) Animal Experiments Local Ethics Committee (HADTEK) (68489742-604.01.03-E.18528, date: 23.10 .2020$)$, and the study was conducted in the Samsun Health Practices and Research Center Pathology Laboratory.

After EC preliminary models obtained from freshly frozen cadaveric cattle heads at similar size were thawed at room temperature $\left(22^{\circ} \mathrm{C}\right), 4 \mathrm{EC}$ models were prepared in the form of a ring (approximately 2 -cm-long segments) in a way that the canal and skin integrity were preserved.

Lithium BB (CR927), Alkaline (LR736), Silver-oxide (SR736), and Zinc-air (PR41) BBs, respectively, were placed in the channel of each EC model with the negative poles in contact with the skin. All EC models were wetted with saline spray $(\mathrm{pH}: 6.8)$ for 2 puffs/30 min for 24 hours. The size and different characteristics of BBs are summarized in Table 1.

BBs were removed from all EC models with forceps at the end of the $3^{\text {rd }}, 6^{\text {th }}, 12^{\text {th }}$, and $24^{\text {th }}$ hours, and their voltages were measured with a digital voltmeter (UNI-T UT 33D Digital Auto Range Multimeter, Dongguan City, China), tissue $\mathrm{pH}$ values were determined with litmus papers (Merck KGaA, Darmstadt, Germany), and tissue temperatures were measured and recorded with a digital infrared thermometer (Bosch PTD 1, Malaysia). All measurements were repeated twice, and the BBs were returned to their places. The visual damage at the end of each time period was photographed. All EC models were examined single-blindly by a pathologist for the depth of necrosis at the end of 24 hours and BBs were removed.

\section{RESULTS}

Gas bubbles and brown discoloration were observed after 1.5 hours in the EC models with lithium, alkaline, and silver-oxide BBs, and after 2.5 hours in the Zinc-air BB EC model. The least visual damage was detected in the EC model in which a zinc-air BB was placed at the end of 24 hours (Figure 1, 2).

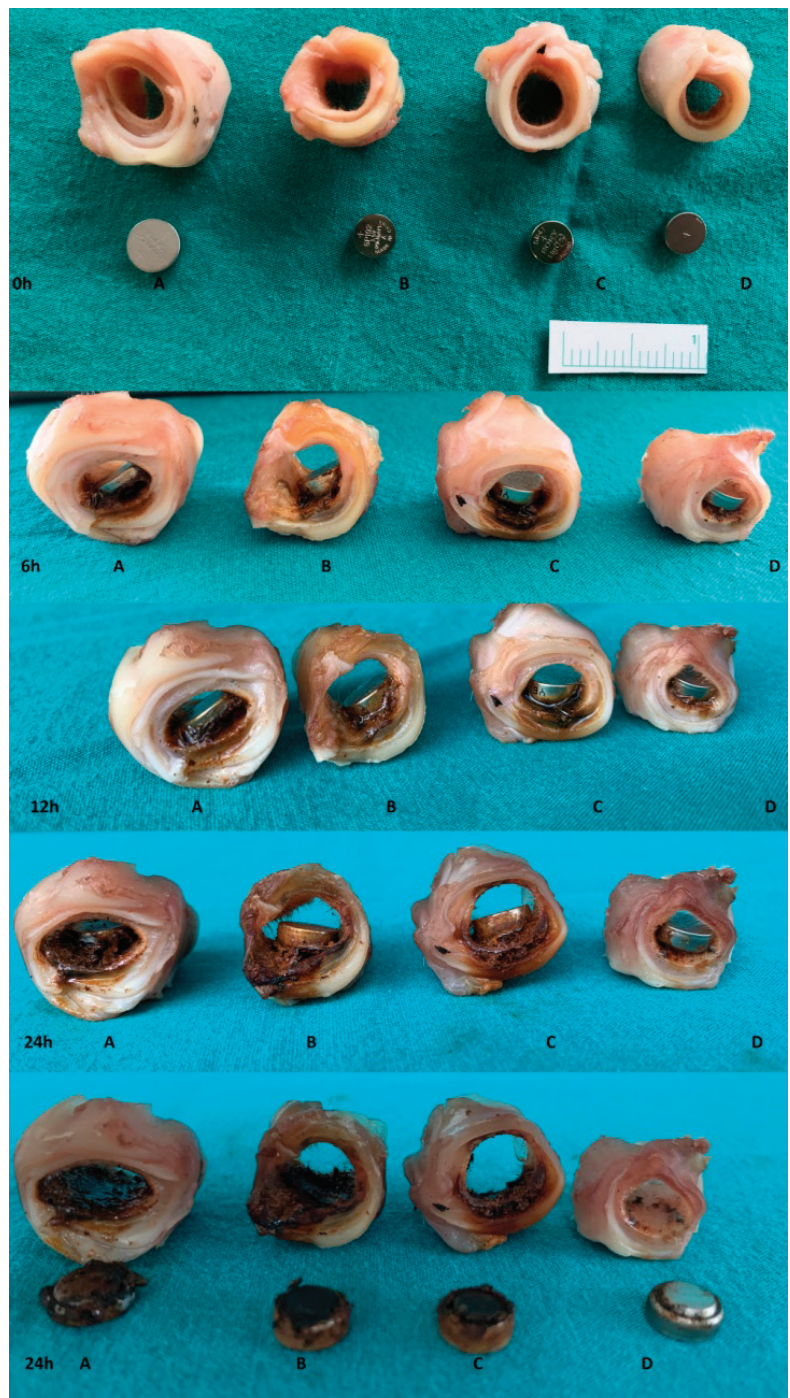

Figure 1: Visual changes of $B B s$ at $0,6,12,24^{\text {th }}$ hours. A: Lithium, B: Alkaline, C: Silver-oxide, D: Zinc-air.

Table 1: BB types and their properties.

\begin{tabular}{|c|c|c|c|c|c|c|}
\hline BB types & IEC* & $\begin{array}{l}\text { Dimensions } \\
\text { Dia. x h. (mm) }\end{array}$ & Voltage (V) & Positive electrode & Negative electrode & Electrolyte \\
\hline Lithium & CR927 & $9.5 \times 2.7$ & 3 & Manganese dioxide & Lithium & Organic \\
\hline Alkaline & LR736 & $7.9 \times 3.6$ & 1.5 & Manganese dioxide & Zinc & Alkaline \\
\hline Silver-oxide & SR736 & $7.9 \times 3.6$ & 1.55 & Silver oxide & Zinc & Alkaline \\
\hline Zinc-air & PR41 & $7.9 \times 3.6$ & 1.45 & Oxygen & Zinc & Alkaline \\
\hline
\end{tabular}

*: International Electrotechnical Commission 


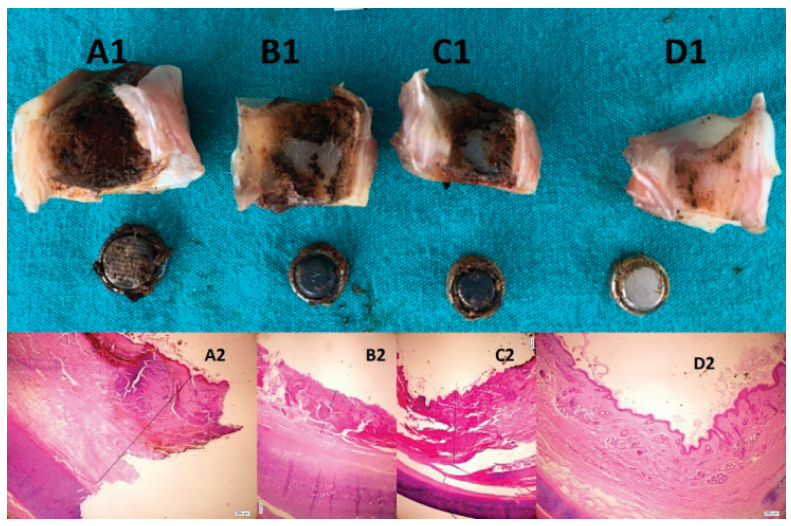

Figure 2: Images of BBs extracted from tissue at the end of 24 hours (A1: Lithium, B1: Alkaline, C1: Silver-oxide, D1: Zinc-air). After 24 hours, pathological images of A2: Lithium, B2: Alkaline, C2: Silver-oxide, D2: Zinc-air ( $\times 40$ magnification; H\&E paint; Olympus light microscope shot using DP2 program, Olympus Corp. Shinjuku, Tokyo, Japan). Necrosis depth: A2: $1983 \mu \mathrm{m}, \mathrm{B2}: 854 \mu \mathrm{m}, \mathrm{C2}: 1420 \mu \mathrm{m}, \mathrm{D2}$ : normal epithelium

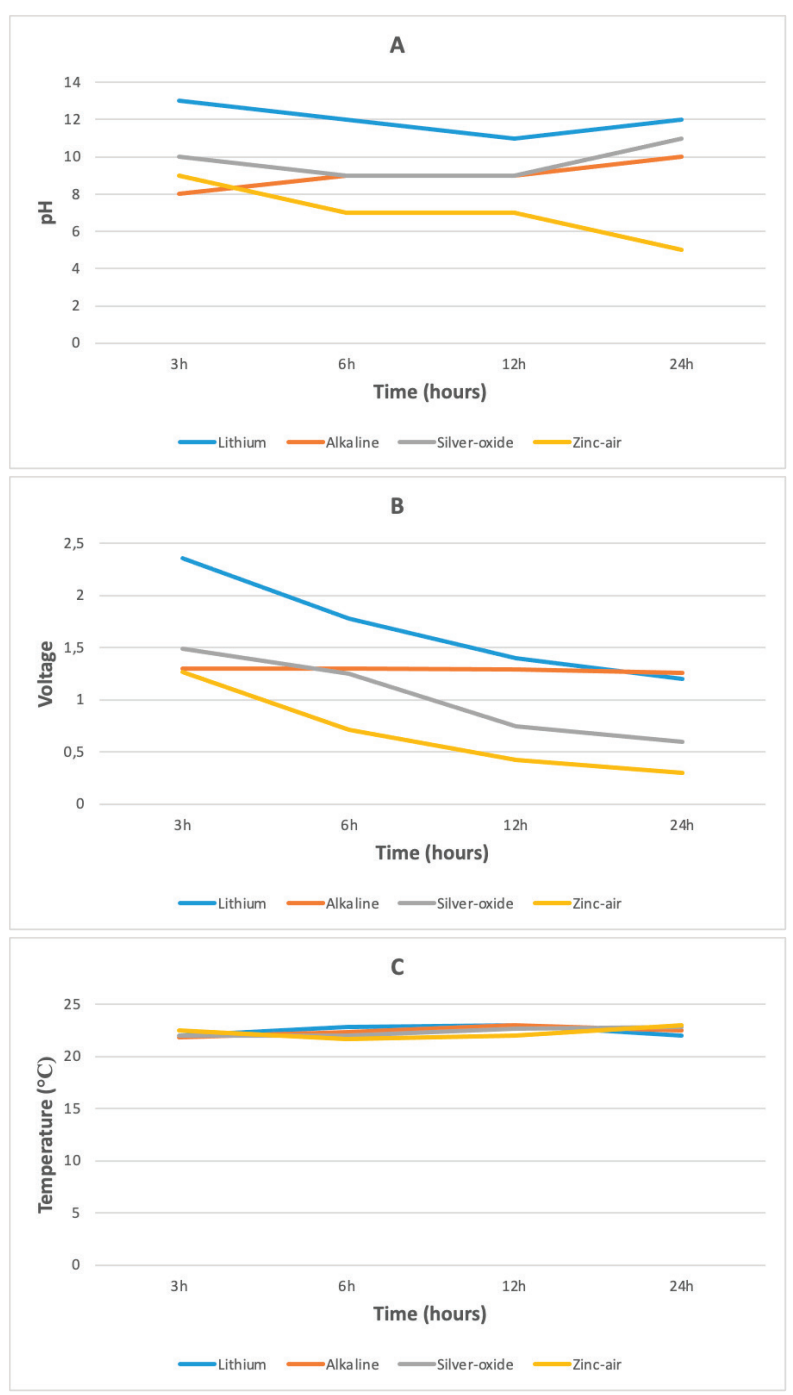

Figure 3: BB tissue $\mathrm{Ph}(\mathrm{A})$, voltage (B), and temperature (C) change values measured according to hours in EC models.
In the $\mathrm{EC}$ model with Lithium $\mathrm{BB}$, the most significant $\mathrm{pH}$ elevation $(\mathrm{pH}: 13)$ was detected at the $3^{\text {rd }}$ hour, and the most significant voltage drop was observed between 3-6 hours. In the $\mathrm{EC}$ model with alkaline $\mathrm{BB}$, the most significant $\mathrm{pH}$ elevation $(\mathrm{pH}: 10)$ was detected at the $24^{\text {th }}$ hour, and no significant voltage changes were detected in all time periods. In the EC model with silver-oxide $\mathrm{BB}$, it was observed that the $\mathrm{BB}$ voltage decreased in direct proportion to time, and the $\mathrm{pH}$ changes did not accompany the voltage decrease in harmony. In the EC model with Zinc-air BB, the decreasing voltage was accompanied by a slight increase in $\mathrm{pH}$ value $(\mathrm{pH}: 9)$ at the $3^{\text {rd }}$ hour, and it was detected that the $\mathrm{pH}$ value was around neutral $\mathrm{pH}$ from the $6^{\text {th }}$ hour. No significant changes were detected in tissue temperatures in all time periods. The changes in $\mathrm{pH}$, voltage, and temperature of $\mathrm{BBs}$ at $3,6,12$, and $24^{\text {th }}$ hours are shown in Figure 3.

The depth of necrosis was measured as $1983 \mu \mathrm{m}$ in lithium BB model, $854 \mu \mathrm{m}$ in alkaline, and $1420 \mu \mathrm{m}$ in silver-oxide at the end of 24 hours in EC models that were examined singleblind. No tissue necrosis was detected in the Zinc-air BB model (Figure 2).

\section{DISCUSSION}

The use of BBs has gradually increased in our daily life with advancing technology (4). In particular, children's access to them has become easier with the reduction of BB size, and it has become easier for them to get stuck in narrow areas, such as the EC and nasal cavity. BBs stuck in EC are also frequently experienced by the elderly population, who use hearing aids $(12,13)$. It is important for the clinician, who will remove the $\mathrm{FB}$, to know what the foreign body in the EC is to prevent possible complications (11).

It was reported that approximately $20 \%$ of patients using hearing aids experience many problems $(12,14)$. It was also reported that approximately half of the BB-induced injuries in elderly adults occur because of the dislocation of device batteries and their jamming in the EC in patients using hearing aids; even patients mistook the batteries for the device itself and placed them in the EC $(12,15,16)$. One article reported that in three cases, a hearing-aid BB stuck in an ear canal induced necrosis and edema in the EC, which were detected at the time of diagnosis. This progressed to a granulomatous reaction in the following weeks (12). It was also reported that tympanic membrane perforation, cartilage and bone necrosis, meatal stenosis, resistant otitis externa, and middle and inner ear damage might develop in patients with delayed diagnosis (17).

It was reported that $85.9 \%$ of 17,325 EC foreign body admissions (2,887/year) recorded in the UK between 2010 and 2016 consisted of pediatric patients (3). It was also reported that a total of 3.748 individuals under the age of 18 were admitted with BBs in EC between 1990 and 2009 in the USA (18). Lithium BBs that have a diameter of $20 \mathrm{~mm}$ are the most commonly detected BBs in case reports and case series in the literature. They result in serious complications, and may result 
in mortality when swallowed (19). It was observed that lithium $B B s$ begin to cause damage to the aerodigestive system mucosa within as few as 2 hours $(20,21)$.

Jatana et al. (7) reported that lithium, alkaline, and silver-oxide BBs caused significant damages in the mucosa in cadaveric porcine esophagus models, but zinc-air BB did not cause any visible changes. Sancaktar et al. (1) observed that visual damage because of BBs started at the $15^{\text {th }}$ minute in cadaveric sheep nasal septum models, the maximum change was detected in Lithium BBs, and the least was in zinc-air BBs at the end of the $6^{\text {th }}$ hour. They also found that the depth of necrosis in the mucoperichondrium was caused by lithium, alkaline, silveroxide, and zinc-air BB, respectively (1). The effects of BBs on mucosal structures, such as the esophagus and nasal septum, were investigated in these studies. In our study, however, BB injuries were investigated in EC models that had a different anatomical and histological structure, and similar results were obtained. In porcine esophagus modeling, $3 \mathrm{~V}$ lithium BBs and $1.5 \mathrm{~V}$ smaller BBs were compared, and the tissue damage scores of small BBs were found to be slower but at the same level (22). In our EC modeling, no histological damage was detected to EC skin after 24 hours only in $1.45 \mathrm{~V}$ zinc-air BB.

The tissue damage due to button batteries occurs through three mechanisms, the first being the penetration of the alkaline electrolyte solution in the battery into deep tissues as a result of alkaline necrosis in the tissue, the second being the damage caused by cumulative electrical current, and the third being because of the pressure necrosis of the button battery (17, 20). It is already known that BBs cause more rapid and serious damage in humid environments such as the mucosa (23). The resistance of an electrolysis cell depends on the electrode area (a), the electrode distance (d), and the conductivity of the medium $(\sigma)(r(c)=d / a \sigma)$ (23). The distance between the electrodes reduces the resistance and the current increases. Although the proximity of the negative and positive ends is technically advantageous because of the small dimension, it can also cause rapid electrochemical reactions in narrow annular organs. The BB negative pole is the part held responsible for the damage (16). It causes the formation of hydroxide ions around the negative pole that is in contact with the tissue and then elevated basic $\mathrm{pH}$, which results in local burns $(24,25)$. For this reason, it is necessary to examine the tissue that is close to the negative pole of the BB more carefully. The fluid that leaks from the damaged tissue increases the electrolyte concentration in the medium and causes the electrolysis reaction to increase (24).

BBs are defined as small single-cell batteries. Their diameters are usually larger (5.8 -30 $\mathrm{mm}$ ) than their heights (1.2-5.4 $\mathrm{mm}$ ), and voltages range between 1.45 and $3 \mathrm{~V}$, depending on their models (19). It was speculated in previous studies that if the residual voltage of $\mathrm{BBs}$ is higher than $1.2 \mathrm{~V}$, they may cause damage (1). Alkaline, silver oxide, and zinc-air batteries are smaller in size and have less voltage than lithium batteries. Although damages were reported in the literature mostly due to lithium BBs with a diameter of $20 \mathrm{~mm}$ or larger, it should be known that smaller BBs may also cause mucosal damage (22). In a meta-analysis of 6.262 swallowed BBs, it was found that more than $90 \%$ of the cases were BBs less than $20 \mathrm{~mm}$ in diameter (22).

It was reported in the literature that serious complications regarding BBs occur mostly after swallowing or inhalation (8). Cases that result in septum perforation, nasal synechia, esophageal structure and perforation, vocal cord paralysis, aortic perforation, or worse, death can be listed among these (26). Since BBs are more life-threatening than other foreign bodies, they must be evaluated urgently.

Although EC is not as wet as the mucosal structures, the damage might be accelerated because of BB discharges based on bleeding that occurs during unsuccessful removal attempts in some healthcare centers, depending on the duration of stay of BBs. Also, ear drops that are given mistakenly might accelerate the damage done by BBs that are forgotten in EC or whose removal is delayed. Although the complications due to BBs stuck in the EC seem to be rarer compared to those compressed in the airway, such as the esophagus or nose, the rapid spread of the use of $\mathrm{BBs}$, the high child population in rural areas, as in Turkey, and the presence of refugee children, whose number has increased rapidly in recent years, all increase the importance of addressing these risks.

Special attention should be paid to all BB foreign bodies, including when they are stuck in EC, and cases must be referred to specialist centers urgently.

\section{CONCLUSION}

Because of the different chemical structures and voltages of BBs, their effects on tissues may also be different. According to the results of our study, although many believe that zinc-air BBs do not cause as much damage as lithium, alkaline, and silver oxide, it is not reasonable to argue that one BB type is less harmful than others, based on this in vitro study. These results must be confirmed in experiments more comprehensively in advanced in vivo studies. The fact that all BBs should be removed from their locations as soon as possible remains true.

Ethics Committee Approval: The ethical aspect of this study was approved by the Ondokuz Mayıs University (OMU) Animal Experiments Local Ethics Committee (HADTEK) (68489742-604.01.03-E.18528, date: 23.10.2020).

Informed Consent: Written informed consent was obtained.

Peer-Review: Externally peer-reviewed.

Author Contributions: Conception/Design of Study- G.A.; Data Acquisition- G.A., M.B.; Data Analysis/Interpretation- G.A., M.B.; Drafting Manuscript- G.A.; Critical Revision of Manuscript- M.B.; Final Approval and Accountability- G.A.

Conflict of Interest: Authors declared no conflict of interest.

Financial Disclosure: Authors declared no financial support. 


\section{REFERENCES}

1. Sancaktar ME, Bayraktar C, Bakırtaş M. Injury Mechanism of Button Batteries in the Nasal Cavity and Possible Mitigation Strategies During Impaction. Laryngoscope 2020;130(10):2487-93.

2. Buttazzoni E, Gregori D, Paoli B, Soriani N, Baldas S, Rodriguez $\mathrm{H}$, et al. Susy Safe Working Group. Symptoms associated with button batteries injuries in children: An epidemiological review. Int J Pediatr Otorhinolaryngol 2015;79(12):2200-7

3. Morris S, Osborne MS, McDermott AL. Will children ever learn? Removal of nasal and aural foreign bodies: a study of hospital episode statistics. Ann R Coll Surg Engl 2018;100(8):1-3.

4. Thabet MH, Basha WM, Askar S. Button battery foreign bodies in children: hazards, management, and recommendations. Biomed Res Int 2013;2013:846091.

5. Lin VY, Daniel SJ, Papsin BC. Button batteries in the ear, nose and upper aerodigestive tract. Int J Pediatr Otorhinolaryngol 2004;68(4):473-9.

6. Litovitz TL. Battery ingestions: product accessibility and clinical course. Pediatrics 1985;75(3):469-76.

7. Jatana KR, Rhoades K, Milkovich S, Jacobs IN. Basic mechanism of button battery ingestion injuries and novel mitigation strategies after diagnosis and removal. Laryngoscope 2017;127(6):1276-82.

8. Huang T, Li WQ, Xia ZF, Li J, Rao KC, Xu EM. Characteristics and outcome of impacted button batteries among young children less than 7 years of age in China: a retrospective analysis of 116 cases. World J Pediatr 2018;14(6):570-5.

9. Premachandra DJ, McRae D. Severe tissue destruction in the ear caused by alkaline button batteries. Postgrad Med J 1990;66(771):52-3.

10. Penteado SP, Bento RF. Performance analysis of ten brands of batteries for hearing aids. Int Arch Otorhinolaryngol 2013;17(3):291-304.

11. Svider PF, Vong A, Sheyn A, Bojrab DI 2nd, Hong RS, Eloy JA, et al. What are we putting in our ears? A consumer product analysis of aural foreign bodies. Laryngoscope 2015;125(3):709-14.

12. Strachan DR, Kenny H, Hope GA. The hearing-aid battery: a hazard to elderly patients. Age Ageing 1994;23(5):425-6.

13. Holdstein Y, Mazzawi S, Watad W, Shupak A. Wrong impression: middle ear foreign body following hearing aid fitting. Otolaryngol Head Neck Surg 2013;149(4):647-8.
14. Wasson JH, Gall V, McDonald R, Liang MH. The prescription of assistive devices for the elderly: practical considerations. J Gen Intern Med 1990;5(1):46-54.

15. Jatana KR, Litovitz T, Reilly JS, Koltai PJ, Rider G, Jacobs IN. Pediatric button battery injuries: 2013 task force update. Int J Pediatr Otorhinolaryngol 2013;77(9):1392-9.

16. Svider PF, Johnson AP, Folbe AJ, Carron MA, Eloy JA, Zuliani G. Assault by battery: battery-related injury in the head and neck. Laryngoscope 2014;124(10):2257-61.

17. Bhisitkul DM, Dunham M. An unsuspected alkaline battery foreign body presenting as malignant otitis externa. Pediatr Emerg Care 1992;8(3):141-2.

18. Sharpe SJ, Rochette LM, Smith GA. Pediatric battery-related emergency department visits in the United States, 1990-2009. Pediatrics 2012;129(6):1111-7.

19. Labadie M, O'Mahony E, Capaldo L, Courtois A, Lamireau T, Nisse $P$, et al. Severity of button batteries ingestions: data from French Poison Control Centres between 1999 and 2015. Eur J Emerg Med 2018;25(4):e1-8.

20. Litovitz T, Whitaker N, Clark L. Preventing battery ingestions: an analysis of 8648 cases. Pediatrics 2010;125(6):1178.

21. Anfang RR, Jatana KR, Linn RL, Rhoades K, Fry J, Jacobs IN. pHneutralizing esophageal irrigations as a novel mitigation strategy for button battery injury. Laryngoscope 2019;129(1):49-57.

22. Jatana KR, Barron CL, Jacobs IN. Initial clinical application of tissue $\mathrm{pH}$ neutralization after esophageal button battery removal in children. Laryngoscope 2019;129(8):1772-6

23. Voelker J, Voelker C, Engert J, Schendzielorz P, Hagen R, Rak K. Severe tracheobronchial harm due to lithium button battery aspiration: An in vitro study of the pathomechanism and injury pattern. Int J Pediatr Otorhinolaryngol 2020;139:110431.

24. Eliason MJ, Melzer JM, Winters JR, Gallagher TQ. Identifying predictive factors for long-term complications following button battery impactions: A case series and literature review. Int J Pediatr Otorhinolaryngol 2016;87:198-202.

25. Shaffer AD, Jacobs IN, Derkay CS, Goldstein NA, Giordano T, Ho $\mathrm{S}$, et al. Management and Outcomes of Button Batteries in the Aerodigestive Tract: A Multi-institutional Study. Laryngoscope 2021;131(1):E298-306.

26. Liao W, Wen G, Zhang X. Button battery intake as foreign body in Chinese children: review of case reports and the literature. Pediatr Emerg Care 2015;31(6):412-5. 